\title{
Stock identification of tiger tooth croaker Otolithes ruber (Schneider, 1801) along the Indian coast using truss network analysis
}

\author{
E. M. CHHANDAPRAJNADARSINI ${ }^{1}$, SUSHANTA KUMAR CHAKRABORTY ${ }^{2}$, SUBAL \\ KUMAR ROUL ${ }^{3}$, ASHOK KUMAR JAISWAR ${ }^{2}$, G. B. SREEKANTH ${ }^{4}$ AND SAMBID SWAIN ${ }^{5}$ \\ ${ }^{1}$ Madras Research Centre of ICAR-Central Marine Fisheries Research Institute, R. A. Puram, Chennai - 600028 \\ Tamil Nadu, India \\ ${ }^{2}$ ICAR-Central Institute of Fisheries Education, Versova, Mumbai - 400 061, Maharashtra, India \\ ${ }^{3}$ ICAR-Central Coastal Agricultural Research Institute, Ela, Old Goa - 403 402, Goa, India \\ ${ }^{4}$ Department of Fisheries, Centurion University, Parlakhemundi, Gajapati - 761 211, Odisha, India \\ e-mail: elinamadhu1@gmail.com
}

\begin{abstract}
The tiger toothed croaker Otolithes ruber (Schneider, 1801) of the family Sciaenidae is a demersal fish that contributes significantly to the marine fish landings of India. To identify stock units of $O$. ruber based on body shape morphometry, truss network analysis was carried out based on specimens collected from four selected locations, two each from east coast (Digha and Chennai along Bay of Bengal) and the west coast (Cochin and Ratnagiri along Arabian Sea) of India. A total of 20 truss distances along the fish surface, including head, mid body and posterior region were measured and transformed measurements were subjected to factor analysis and discriminant function analysis. The bivariate plot score of factor analysis indicating two distinct stocks on both the coasts may be the consequence of geographical isolation and different environmental conditions along the Bay of Bengal (east coast) and Arabian Sea (west coast). The Ratnagiri and Cochin population showed considerable mixing which indicated the presence of a unit stock along the west coast. However, existence of strong morphometric differentiation between Digha and Chennai populations indicated two separate spawning populations in the Bay of Bengal. In the cross-validation of Discriminant function analysis, the most well classified group was Digha population (97.85\%). The present study suggests the possible existence of three stocks of $O$. ruber, one in west coast (Cochin and Ratnagiri) and two in east coast (Digha and Chennia) which can be considered while formulating effective management strategies for the species.
\end{abstract}

Keywords: Discriminant analysis, Factor analysis, Otolithes ruber, Stock identification, Truss network system

\section{Introduction}

Stock identification defined as the separation of self sustaining components within fish species is the basic need of fisheries resource management (Cadrin, 2005). Information on stock structure is one of the prerequisites of reliable management of exploited fishery resources as stock based management practices need to be followed to achieve sustainable yield, avoid recruitment failures and rebuild overfished stocks (Turan et al., 2006). Fisheries resource management framework without proper information on stock structure has led to an erosion of spawning stock components resulting in a loss of genetic diversity and other ecological consequences (Begg et al., 1999). Therefore, for effective fisheries management, it is very much essential to study stock structure of a species, as each stock should be managed separately to optimise their yield.

One of most widely used stock identification techniques is analysis of morphometric traits and it is an essential prerequisite for further confirmations (Cadrin, 2000) to elucidate spatial discreteness. Studies have revealed that the truss network system provided a more accurate classification of individuals than traditional morphometric methods (Strauss and Bookstein, 1982; Winans, 1987; Schweigert, 1990; Roby et al., 1991) as it helps to overcome size dependent variation and takes into account the shape associated variables. It is effective in describing the shape of the fish under study (Cavalcanti et al., 1999). Moreover, it has been widely used for the discrimination of intra and inter-population shape variations (Strauss and Bookstein, 1982; Rohlf and Bookstein, 1990; Bronte et al.,1999).

Sciaenids form one of the important constituents of the marine fish landings of India landed mainly by trawlers and contribute about $15 \%$ to the total demersal finfish resources (CMFRI, 2018). Tiger toothed croaker Otolithes ruber (Schneider, 1801) is a commercially important 
medium sized species, widely distributed in tropical, subtropical and temperate seas, including the Persian Gulf and Oman Sea, Indian and Pacific Oceans, China and the Malayan archipelago (Brash and Fennessy, 2005). It is found all along the Indian coast at depths between 10 and $40 \mathrm{~m}$ (Sasaki, 2001). However, the information on the stock structure of the species is not well understood. Until now, stock assessment of $O$. ruber was conducted on a regional basis (Chakraborty et al., 2000; Santoshkumar et al., 2017) where data may represent multiple stocks and this violates many fundamental assumptions of fisheries management. If unique stocks can be identified, data on such populations can be used independently for stock assessments to formulate effective fisheries management. Therefore, the present study was carried out to identify independent stocks of $O$. ruber from all along the Indian coast based on morphometric characteristics employing a truss network system.

\section{Materials and methods}

Study area and sample collection

Altogether 385 specimens of $O$. ruber were collected from commercial landings at four locations based on the availability of the species along the Indian coast i.e., Digha (West Bengal) and Chennai (Tamil Nadu) from the east coast and Ratnagiri (Maharashtra) and Cochin (Kerala) from the west coast of India (Table 1, Fig. 1) between September, 2011 and February, 2012. The details of the samples collected from each location are presented in Table 1.

\section{Truss morphometric measurements}

A good quality digital camera, Cyber shot DSC-W300 (Sony, Japan) was used for acquiring the images of the fish samples as digital records provide a complete archive of body shape (Cadrin and Friedland, 1999). The truss network analysis, based on a series of truss network measurements or distances that form a regular pattern of connected quadrilaterals was selected for both body and skull of fish. These distances were measured on the basis of morphologically significant anatomical locations on fish body called as 'landmarks'. A truss network consisting of a total of 20 truss distances by collating 10 landmarks (Fig. 2) were used in the present study. The distances were extracted from the digitised image using a combination of two softwares, tpsDig2 V2.1 (Rohlf, 2006) and Paleontological Statistics (PAST) (Hammer et al., 2001).

Table 1. Details of samples of $O$. ruber collected from various locations along the east and west coasts of India

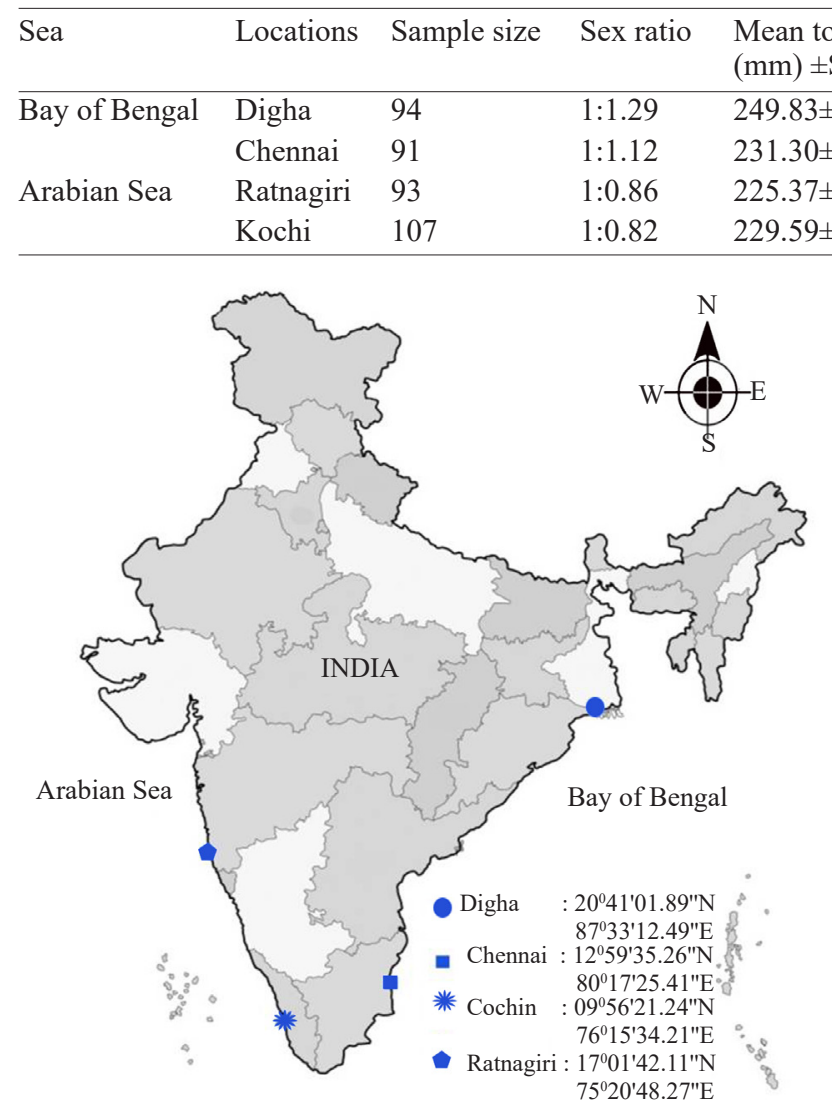

Fig. 1. Map showing the sampling locations

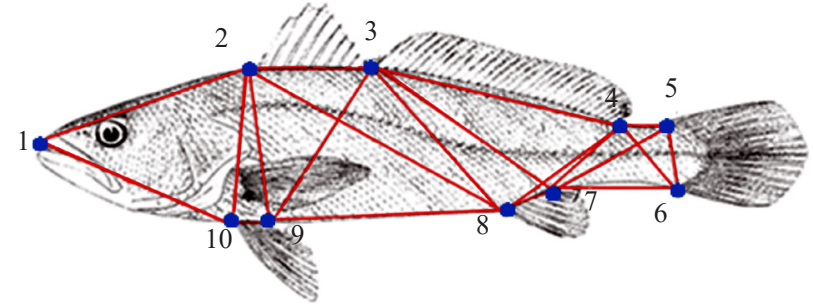

Fig. 2. Truss network of $O$. ruber showing the twenty truss distances extracted from 10 point truss

Transformation of truss distances for removing size dependent variation

All the truss measurements were first tested for outliers and 20 observations were removed based on Cook's distance estimates (Cox and Small, 1978) using the PROC ROBUSTREG procedure of SAS software (SAS, 2008) as they may distort the general tendency in the size distribution. A transformation was used to reduce 
the correlation between body size and truss distances and convert size-dependent truss distances to size independent shape variables. The size dependent variation was eliminated using an allometric approach of Reist (1985) with some modification, i.e. location-wise $\mathrm{SL}_{\text {mean }}$ was taken in the place of overall mean (Swatipriyanka Sen et al., 2011).

$\mathrm{M}_{\text {trans }}=\log \mathrm{M}-\beta\left(\log \mathrm{SL}-\log \mathrm{SL}_{\text {mean }}\right)$

where, $M_{\text {trans }}$ : Transformed truss distance, M: Original truss distance, $\beta$ : Within-group slope of the regressions of $\log \mathrm{M}$ on $\log \mathrm{SL}, \mathrm{SL}$ : Standard length of the fish, $\mathrm{SL}_{\text {mean }}$ : Location-wise mean standard length

Multivariate analysis

Correlation coefficients between the transformed truss distances and the standard length of the fish were estimated to validate efficacy of transformation in removing the size dependent variation. The multinomial Mardia's test was carried out to check whether the data follow a multivariate normal distribution (Cox and Small, 1978). Then, the truss distances were subjected to factor analysis (Hatcher, 2003) using PROC FACTOR procedure of SAS (SAS, 2008) for identifying the independent stocks along the Indian coast. Thus, three factor analysis was carried out, one for between the coast and another two within each coast to investigate the stock structure of O. ruber. Significant factors were extracted for both coasts and locations within a coast by employing a Maximum likelihood method and retained factors were subjected to rotation procedure by VARIMAX (orthogonal) rotation
(SAS, 2008). The rotated factors were subjected to scratching procedure as described by Hatcher (2003) to identify the high loadings variables for a given factor. A truss variable is said to be heavily loaded on a given factor if the factor loading is 0.4 or greater (Hatcher, 1994) and those variables which has high loadings on all the three factors were not considered. Classification of individuals by cross-validation using discriminant analysis was carried out using the PROC DISCRIM procedure of SAS (SAS, 2008).

\section{Results}

There was no significant correlation $(p>0.05)$ between transformed truss distances and standard length indicating that the effect of body length had been successfully removed by the allometric transformation.

Differentiation of stocks from east and west coasts of India

The factor analysis of transformed truss distances indicated that the first two factors together explained $80.63 \%$ of morphometric variation. First factor accounted for $71.49 \%$ of total variation and the truss distances with high loading factors were 1-10, 2-8, 3-7, 7-8 and 8-9 (Table 2, Fig. 4). These truss distances were located on anterior half of the body. Second factors explained $9.14 \%$ of total variation and the truss distances, 4-5, 4-6, 5-6, 5-7 and 6-7 concentrated in the caudal region which showed meaningful loading (Table 1, Fig. 4). These highly loaded truss distances were the straight and oblique depth measurements of the fish body and they were located on

Table 2. The rotated factor pattern for the truss distances in factor analysis

\begin{tabular}{llll}
\hline Truss distances & Factor1 & Factor2 & Factor3 \\
\hline $1-2$ & 0.58278 & 0.23825 & 0.4033 \\
$1-10$ & 0.60623 & 0.17764 & 0.36772 \\
$2-3$ & 0.29268 & 0.2286 & 0.46327 \\
$2-8$ & 0.76899 & 0.38415 & 0.38689 \\
$2-9$ & 0.36845 & 0.22712 & 0.8622 \\
$2-10$ & 0.38482 & 0.19016 & 0.85371 \\
$3-4$ & 0.76713 & 0.43302 & 0.22701 \\
$3-7$ & 0.8721 & 0.33987 & 0.28613 \\
$3-8$ & 0.82759 & 0.41346 & 0.31723 \\
$3-9$ & 0.30216 & 0.19843 & 0.77174 \\
$4-5$ & -0.0244 & 0.82145 & -0.0618 \\
$4-6$ & 0.27595 & 0.58721 & 0.06111 \\
$4-7$ & 0.45013 & 0.66172 & 0.33081 \\
$4-8$ & 0.55174 & 0.54426 & 0.38415 \\
$5-6$ & 0.28535 & 0.75422 & 0.20427 \\
$5-7$ & 0.18968 & 0.97309 & 0.13081 \\
$6-7$ & 0.30542 & 0.81255 & 0.10054 \\
$7-8$ & 0.43081 & -0.072 & 0.25797 \\
$8-9$ & 0.55027 & 0.20342 & 0.3154 \\
$9-10$ & 0.07379 & -0.0662 & 0.24196 \\
\hline
\end{tabular}


anterior half including head and mid-body and caudal region of the fish body. Bivariate plot of second factor against first factor clearly separated the clusters of the populations of both east and west coasts indicating significant morphological discrimination between Bay of Bengal and Arabian Sea populations (Fig. 3).

\section{Differentiation of population within the coasts of India}

The factor analysis for locations within east coast indicated that first two factors together explained $72.46 \%$ of total variation with Eigen value of $65.37 \%$ and $7.49 \%$ on first and second factor respectively. The truss variables which showed high loading on the two factors were 1-10, 3-7, 3-8, 7-8, 4-7 and 6-7. Bivariate plot of second factor against first factor revealed a clear separation of Digha and Chennai stocks indicating strong morphometric differentiation. Likewise, Factor analysis for locations within west coast was carried out and the first two factors together explained $61 \%$ of total variation with Eigen value of $43.36 \%$ and $17.64 \%$ for the first and second factors.
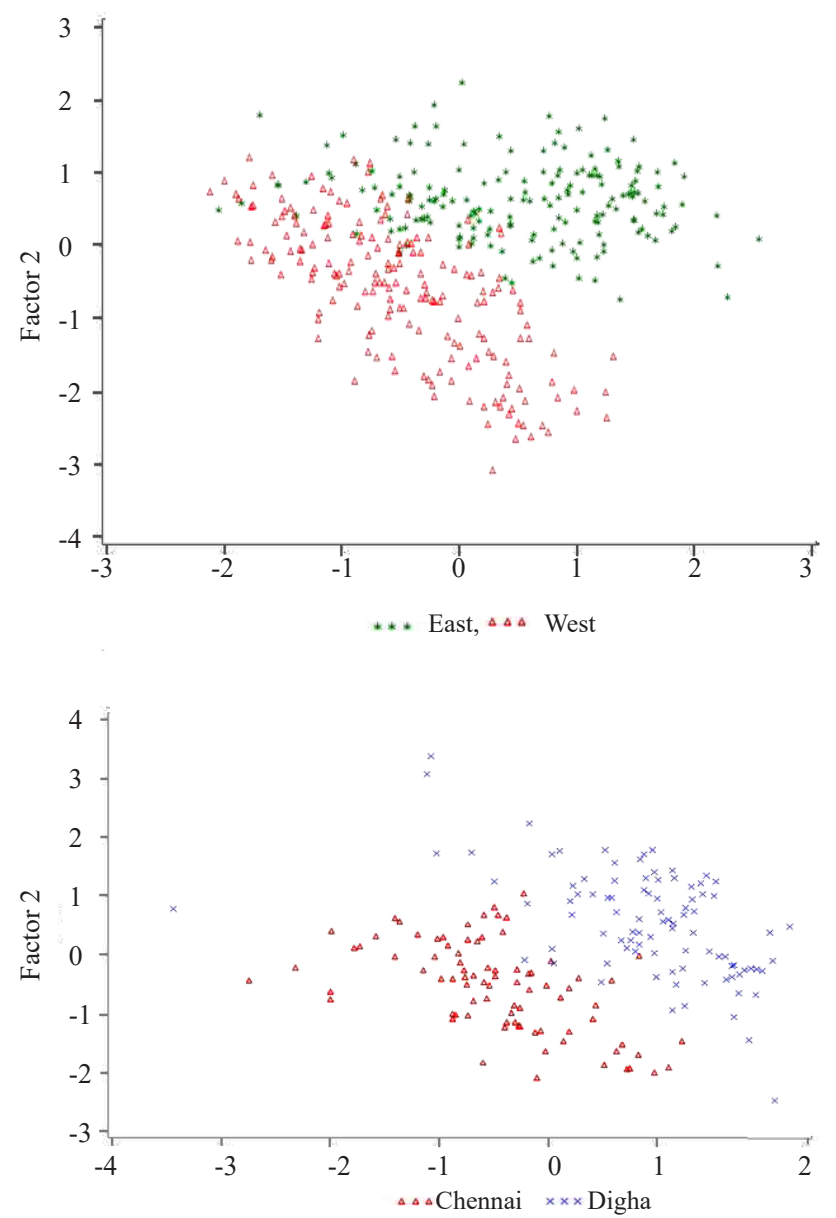

The bivariate plot of second factor against first factor showed an obvious mixing of populations of Cochin and Ratnagiri.

\section{Classification by discriminant function analysis}

The different combinations of truss variables with high loading on the first and second factors was considered for classifying individuals between the coasts and the four sampling locations. The combinations of truss distances that showed minimum amount of miss classification were 5-6, 5-7, 4-6 and 6-7 which belonged to the caudal portion of the body. Coast-wise discriminant function analysis showed $94 \%$ of accuracy in classification whereas location-wise it was $87 \%$. Percentage of fish from each location or coast (in rows) classified by discriminant function analysis are presented in the Table 3.

\section{Discussion}

The present study indicated the existence of significant phenotypic heterogeneity between the populations of
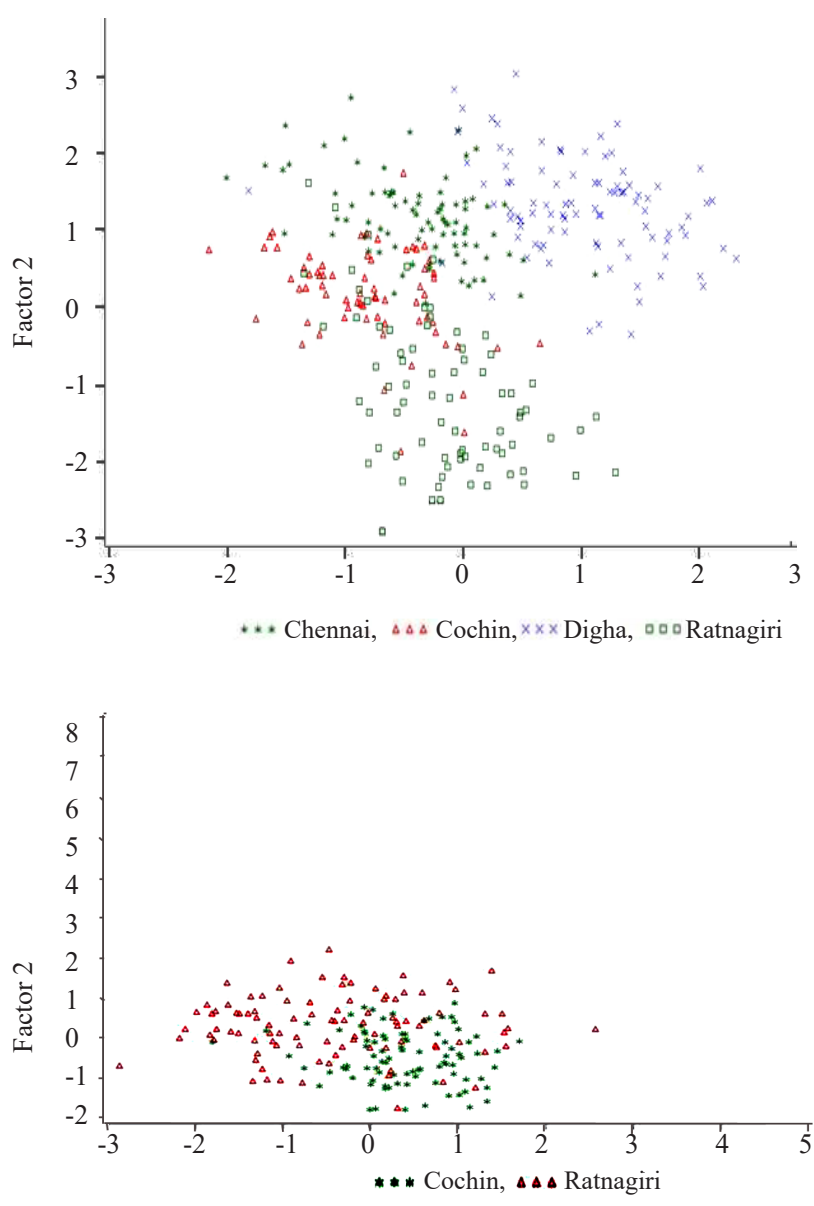

Fig. 3. Bivariate plot of scores on the two factors extracted from 20 point truss measurements of $O$. ruber representing the separations. (a) Coast-wise, (b) Location-wise, (c) Within east coast, (d) Within west coast 
Table 3. Percentage of fish from each location or coast (in rows) classified by discriminant analysis to their respective groups (in columns), 'n' indicates the total no. of samples collected from the respective locations,

\begin{tabular}{|c|c|c|c|c|c|c|}
\hline Coast & East & & West & & $\begin{array}{l}\text { Total rate of } \\
\text { classification (\%) }\end{array}$ & $\begin{array}{l}\text { Total rate of } \\
\text { misclassification (\%) }\end{array}$ \\
\hline East & 88.7 & & 2.6 & & & \\
\hline West & 11.3 & & 97.4 & & 94 & 6 \\
\hline Location & Digha & Chennai & Cochin & Ratnagiri & & \\
\hline Digha & 97.85 & 2.15 & 0 & 0 & & \\
\hline Chennai & 0 & 95.24 & 4.76 & 0 & 87 & 13 \\
\hline Cochin & 0 & 2.22 & 81.11 & 16.67 & & \\
\hline Ratnagiri & 1.02 & 10.02 & 15.31 & 73.47 & & \\
\hline
\end{tabular}

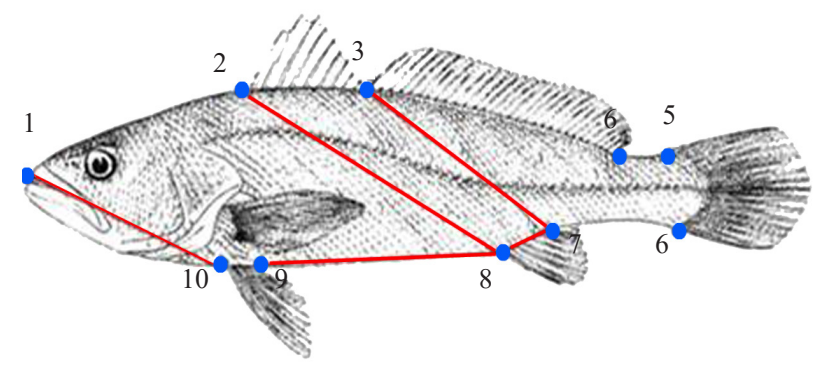

Factor 1

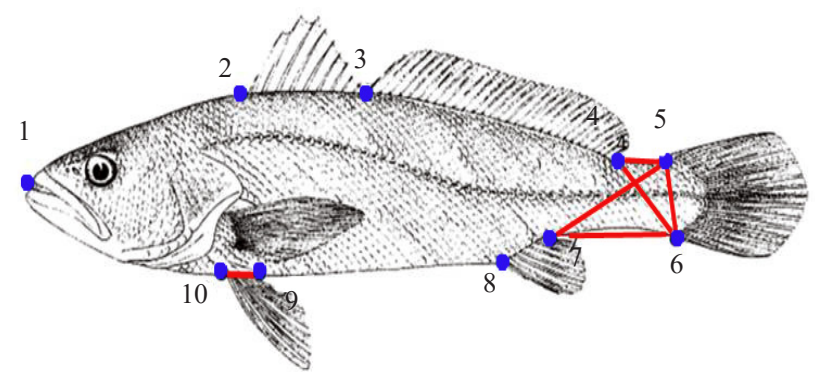

Factor 2

Fig. 4. Truss measurements with meaningful loadings on first two factors of truss network analysis of $O$. ruber

O. ruber from Bay of Bengal and Arabian Sea and the shape related traits belonging to anterior half of the body including head, mid-body and caudal region are found to be efficient for morphological discrimination of these stocks. The strong morphometric differentiation of the populations between coasts suggests the existence of distinct spawning stocks for the species in east and west coasts. Also significant morphological discrimination of population from east coast indicates limited gene flow in the population of $O$. ruber in Bay of Bengal whereas a lack of phenotypic heterogeneity was observed in Arabian Sea. The phenotypic discreteness was likely to represent adaptation to availability and type of prey, geographical isolation, different environmental conditions and interactive effects of environment, selection and genetics on individuals, which are discussed in the following sections.

\section{Availability of prey}

Different prey resources for larvae and juveniles may lead to different adult body shapes, suggesting that there is a phenotypic response to resource availability (Wimberger, 1990). The relative variation in head region may be associated with the availability and type of prey for the species as head length is directly related to prey size (Gatz, 1979). O. ruber is highly carnivorous and it mainly feeds on juveniles of teleosts and shrimps (Suseelan and Nair, 1969). As a predator, it may prefer the most frequently encountered prey, rather than actively seeking the most energetically profitable with fluctuation of predator and prey population in natural environment (Bence and Murdoch, 1986), which may explain the changes in head morphlology. The variation in head region can also be attributed to changes under competition with a closely related species, adapting to the optimal selection of prey (Sreekanth et al., 2012).

\section{Environmental conditions}

In general, fishes are more prone to environmentally induced morphological variation and they show a higher degree of variation within and between populations than other vertebrates (Wimberger, 1990). In the present study, the caudal region is found to be significant in differentiating the east and west coast populations which may be the consequence of phenotypic plasticity in response to hydrological conditions. However, the water turbulence in Bay of Bengal is considerably higher than in the Arabian Sea (Kolla et al., 1976; Chamarthi et al., 2008). There is an observation on the morphological variation in the caudal region of brook charr (Salvelinus fontinalis) from microhabitats differing in water velocity and the fishes from turbulent waters were with a deeper caudal peduncle (Imre et al., 2002). Larval fish may develop different morphologies because of local environmental conditions, 
leading to differences in adult morphology as well. Thus, physico-chemical characteristics of habitat may drive changes in the morphological attributes of native fish populations (Hass et al., 2010). Studies by Sajina et al. (2010) and Swatipriyanka Sen et al. (2011) have also indicated the variation in the caudal region of Megalaspis cordyla and Decapterus russelli from the Arabian Sea and Bay of Bengal. Higher levels of habitat-specific morphological variation seen in this study indicate either assertive mating or limited gene flow between the coasts.

The strong morphological discrimination of populations in Bay of Bengal indicates the possibility of existence of different stocks in Digha and Chennai which may be due to different environmental conditions of the water body. The water flow is significantly high due to the entry of numerous rivers in the north-east coast of India (Digha) which provides a unique habitat for fish in terms of salinity, temperature and water current. A lack of significant morphometric variation within west coast may be due to common environment, lack of proper demarcation of fishing zone and similar genetic origin in the earlier period. However, further molecular genetic studies need to be carried out to confirm these results.

\section{Geographical isolation}

Geographical isolation plays an important role in the development of phenotypic heterogenity within a species which may be due to the synergistic effects of environment, selection and genetics on individual ontogenies (Poulet et al., 2005). The non-migratory and demersal nature of the species might have resulted in discrete populations between the Arabian Sea and Bay of Bengal. However, the low phenotypic differentiation among stocks within west coast and high phenotypic heterogeneity in east coast suggests a direct relationship between morphometric variation and geographical distance. The morphological discrimination of population within coast may be due to the different ecological habitat of northern and southern part of the Bay of Bengal (Bauer et al., 1991; Banse and English, 1994; Seears et al., 2012; Karati, 2013). Thus, fish stocks are assumed to be distributed in space as gradients (Murta et al., 2008) and geographical separation which is evident from the present study underlines the same.

Morphometric studies help in providing greater insight into discrimination of different fish stocks which have been proved in this study. Truss morphometry revealed the existence of three stocks, two in the east coast and one in west coast suggesting the need of a separate management strategy for their sustainable harvest. The present study also revealed a considerable mixing of population in west coast suggesting implementationn of uniform management measures. The morphometric variation may reflect genetic differences between the fish stocks. Thus, the findings of the present study can be further confirmed based on molecular genetics and biochemical methods. However, based on this morphometric study, development of appropriate management measure should be carried out even if this phenotypic divergence is not reflected by genetic differentiation (Lowe et al., 1998) which may help in sustainable harvest of the resource.

\section{Acknowledgements}

The authors are thankful to Dr. W. S. Lakra, Director, ICAR-CIFE, Mumbai, for providing facilities to conduct the present research work. We are also highly thankful to the faculty of ICAR-CMFRI, Kochi, for helping in sample collection during the study and Dr. Srinivas Jagheerdhar for his kind help in working with SAS programme. The first author acknowledges the financial support from the Indian council of Agricultural Research (ICAR), New Delhi, India, in the form of research fellowship for this work.

\section{References}

Banse, K. and English, D. C. 1994. Seasonality of coastal zone colour scanner phytoplankton pigment in the offshore oceans. J. Geophys. Res., 99 (4): 7323-7345. https://doi. org/10.1029/93JC02155.

Bauer, S., Hitchcock, G. and Olson, D. 1991. Influence of monsoonally-forced Ekman dynamics upon the surface layer depth and plankton biomass distribution in the Arabian Sea. Deep-Sea Research, Part A. Oceanogr. Res. Pap., 38(5): 531-553.

Begg, G. A., Friedland, K. D. and Pearce. J. B. 1999. Stock identification and its role in stock assessment and fisheries management: an overview. Fish. Res., 43(1): 1-8.

Bence, J. R. and Murdoch, W. W. 1986. Prey size selection by the mosquito fish: relation to optimal diet theory. Ecology, 67: 324-336. https://doi.org/10.2307/1938576

Brash, J. M. and Fennessy, S. T. 2005. A preliminary investigation of age and growth of Otolithes ruber from KwaZulu-Natal, South Africa. West. Indian Ocean J. Mar. Sci., 4: 21-28. http://dx.doi.org/10.4314/wiojms.v4i1.28470.

Bronte, C. R., Fleischer, G. W., Maistrenko, S. G. and Pronin, N. M. 1999. Stock structure of Lake Btaikal Omul as determined by whole-body morphology. J. Fish Biol., 54(4): 787-798. https://doi.org/10.1111/j.1095-8649.1999. tb02033.x.

Cadrin, S. X. 2000. Advances in morphometric identification of fishery stocks. Rev. Fish Biol. Fish., 10(1): 91-112.

Cadrin, S. X. 2005. Morphometric landmarks. Stock identification methods: Applications in fishery science. Elsevier Academic Press, San Diego, California, USA, p.153-172. 
Cadrin, S. X. and Friedland, K. D. 1999. The utility of image processing techniques for morphometric analysis and stock identification. Fish. Res., 43(1): 129-139.

Cavalcanti, M. J., Monteiro, L. R. and Lopez, P. R. D. 1999. Landmark based morphometric analysis in selected species of Serranid fishes (Perciformes: Teleostei). Zool. Stud., 38(3): 287-294.

Chakraborty, S. K., Devadoss, P., Manojkumar, P. P., Ferozkhan, M., Jayasankar, P. and Sivakami, S. 2000. Fishery, biology and stock assessment of jew fish resources of India. In: Pillai, V. N. and Menon, N. G. (Eds.), Marine research and management. ICAR-Central Marine Fisheries Research Institute, Kochi, p. 604-616.

Chamarthi, S., Ram, P. S. and Josyula, L. 2008. Effect of river discharge on Bay of Bengal circulation. Mar. Geol., 31(3): 160-168. https://doi.org/10.1080/01490410802265476.

CMFRI 2018. CMFRI Annual Report 2017-18. ICAR-Central Marine Fisheries Research Institute, Kochi, 340 pp.

Cox,D. R. and Small, N. J. H. 1978. Testing multivariate normality. Biometrika, 65 (2): 263-272. https://doi. org/10.1093/biomet/65.2.263.

Gatz, A. J. 1979. Ecological morphology of freshwater stream fishes. Tulane Stud. Zool. Bot., 21(2): 91-124.

Hammer, O., Harper, D. A. T. and Ryan, P. D. 2001. PAST: Paleontological Statistics Software Package for Education and Data Analysis. Palaeontol. Electron., 4 (1): 9 pp.

Hatcher, L. 1994. A step-by-step approach to using the SAS system for factor analysis and structural equation modeling. SAS Institute, Cary, NC, USA, p. 57-125.

Hatcher, L. 2003. A step by step approach to using SAS for factor analysis and structural equational modeling. SAS Institute, Cary, NC, USA, p. 57-125.

Imre, I., McLaughlin, R. L. and Noakes, D. L. G. 2002. Phenotypic plasticity in brook charr: changes in caudal fin induced by water flow. J. Fish Biol., 61(5): 1171-1181 https://doi.org/10.1111/j.1095-8649.2002.tb02463.x.

Karati, K. K. 2013. Ecology of chaetognaths in the Indian EEZ. Ph. D. Thesis, Cochin University of Science and Technology, Kochi,, Kerala, India, 242 pp.

Kolla, V., Moore, D. G. and Curray, J. R. 1976. Recent bottom-current activity in the deep western Bay of Bengal. Mar. Geol., 21(4): 255-270. https://doi.org/10.1016/0025-3227(76)90010-4.

Lowe, S. A., Van-Dornik, D. M. and Winans, G. A. 1998: Geographic variation in genetic and growth patterns of Atka mackerel, Pleurogrammus monopterygius (Hexagrammidae) in the Aleutian Archipelago. Fish. Bull., 96: 502-515.

Murta, A. G., Pinto A. L. and Abaunza P. 2008. Stock identification of horse mackerel (Trachurus trachurus) through the analysis of body shape. Fish. Sci., 89(2): 152-158. DOI: 10.1016/j.fishres.2007.09.026
Poulet, N., Reyjol, Y., Collier, H. and Lek, S. 2005. Does fish scale morphology allow the identification of population of Leuciscus burdigalensis in river Viaur (SW France). Aquat. Sci., 67(1): 122-127.

Reist, J. D. 1985. An empirical evaluation of several univariate methods that adjust for size variation in morphometric variation. Can. J. Zool., 63(6): 1429-1439.

Roby. D., Lambert, J. D. and Sevigny, J. M. 1991. Morphometric and electrophoretic approaches to discrimination of capelin (Mallotus villosus) population in the estuary and Gulf of Saint Lawrence. Can. J. Fish. Aquat. Sci., 48(11): 2040-2050 https:/ / doi.org/10.1139/f91-243.

Rohlf, F. J. 2006. tpsDig2, Version 2.1. http://life.bio.sunysb. edu/morph. Stony Brook, NY: State University of New York, USA

Rohlf, F. J. and Bookstein, F. L. 1990. Proceedings of the Michigan morphometrics workshop. The University of Michigan Museum of Zoology special publication no. 2, The University of Michigan, Ann Arbor, Michigan, USA, $380 \mathrm{pp}$.

Sajina, A. M., Chakraborty, S. K., Jaiswar, A. K., Pazhayamadam, D. G. And Sudheesan, D. 2010. Stock structure analysis of Megalaspis cordyla (Linnaeus, 1758) along the Indian coast based on truss network analysis. Fish. Res., 108(1): 100-105. DOI: 10.1016/j.fishres.2010.12.006.

SAS 2008. SAS/STAT. User's Guide, Version 9.1, vol. 1, $4^{\text {th }}$ edn. SAS Institute, Cary, NC, USA, 943 pp.

Sasaki, K. 2001. Sciaenidae, Croakers (drums). In: Carpenter, K. E. and Niem, V. H. (Eds.), FAO species identification guide for fishery purposes, The living marine resources of the Western Central Pacific, 5(3): 3117-3174.

Santhosh kumar, S., Rajagopalsamy, C. B. T., Jawahar, P., Jayakumar, N. and Pavinkumar, P . 2017. Growth and mortality characteristics of Otolithes ruber (Schneider, 1801) exploited off Thoothukudi Coast, Tamil Nadu. J. Entomol. Zool. Stud., 5(4): 1746-1749.

Schweigert, J. F. 1990. Comparision of morphometric and meristic data against truss network for describing Pacific herring stocks. Am. Fish. Soc. Symp., 7: 47-62.

Seears, H. A., Darling, K. F. and Wade, C. M. 2012. Ecological partitioning and diversity in tropical planktonic foraminifera, BMC Evol. Biol., 12(1): 54.

Sreekanth, G. B., Chakraborty, S. K., Jaiswar, A. K., Nair, J. R., Pazhayamadom, D. G., Renjith, R. K., Ratheesh Kumar and Anuraj, A. 2012. Site specific differences in food and feeding biology of Nemipterus japonicus (Bloch, 1791) along Indian coast. Indian J. Fish., 59(3): 25-31.

Strauss, R. E. and Bookstein, F. L. 1982. The truss: Body form reconstructions in morphometrics. Syst. Zool., 31(2): 113-135.

Suseelan, C. and Somasekharan Nair, K. V. 1969. Food and feeding habits of the demersal fishes off Bombay. Indian $J$. Fish., 16(1 and 2): 56-74. 
Swatipriyanka Sen, Shrinivas, J., Jaiswar, A. K., Chakraborty, S. K., Sajina, A. M. and Dash, G. R. 2011. Stock structure analysis of Decapterus russelli (Ruppell, 1830) from Indian coast using Truss network analysis. Fish. Res., 112(1): 38-43.

Turan, C., Oral, M., Ozturk, B. and Duzguneş, E. 2006. Morphometric and meristic variation between stocks of Bluefish (Pomatomus saltatrix) in the Black, Marmara, Aegean and north-eastern Mediterranean Seas. Fish. Res., 79(1): 139-147. https://doi.org/10.1016/j.fishres.2006.01.015.
Wimberger, P. H. 1990. Plasticity of fish body shape: the effects of diet, development, family, and age in two species of Geophagus (Pisces: Cichlidae). Biol. J. Linn. Soc., 45(3): 197-218. https://doi.org/10.1111/j.10958312.1992.tb00 640.x.

Winans, G. A. 1987. Using morphometrics and meristic characters for identifying stocks of fish. In: Kumpf, H. E.,Vaught, R. N., Grimes, C. B., Johnson, A. G. and Nakamura, E. L. (Eds.), Proceedings of the stock identification workshop, NOAA Tech. Mem., NMFS-SEFC, 199: 135-146.

Date of Receipt $\quad$ : 14.01 .2019

Date of Acceptance : 19.08.2019 